\title{
A new bioassay using Chlorella vulgaris cell density for detecting mycotoxins
}

\author{
M. B. Aboul-Nasr ${ }^{1 *}$, Abdel-Naser A. Zohri ${ }^{2}$ and Enas Mahmoud Amer ${ }^{2}$ \\ ${ }^{1}$ Department of Botany, Faculty of Science, University of Sohag, Egypt. \\ ${ }^{2}$ Department of Botany and Microbiology, Faculty of Science, University of Assiut, Egypt.
}

Accepted 25 November, 2013

\begin{abstract}
Bioassay is an alternative screening technique to evaluate the biotoxicity of the fungal secondary metabolites before any further chemical analyses. In this study, the cell density of Chlorella vulgaris cultures were used to detect the biotoxicity of 108 isolates belonging to seven fungal species. The crude extracts of all toxin producing fungal isolates that were tested inhibited the growth of $C$. vulgaris dramatically after 48 and $72 \mathrm{~h}$ as compared to the control. The crude extracts of the nontoxin producing fungal isolates that were tested showed that there was no significant inhibition of $C$. vulgaris at the three time intervals as compared to the control. These results corresponded to the Bacillus subtilis disk diffusion method. The use of optical density readings of the growth of $C$. vulgaris reflected a rapid, easy and effective tool to detect mycotoxins.
\end{abstract}

Key words: Bioassay, Chlorella, colorimetric, mycotoxins, pathogenicity.

\section{INTRODUCTION}

Mycotoxins are an extremely diverse group of biological compounds of secondary fungal metabolites with low molecular weight (mostly below $700 \mathrm{Da}$ ). The chemical structure and physical properties of these toxins are widely varied. When these toxins are ingested, inhaled or absorbed through the skin, they cause lowered performance, sickness or death in man or animals and birds (Van Egmond and Speijers, 1999).

Biological assay is the determination of the relative strength of a substance by comparing its effect on a test organism with that of a standard preparation. It has become increasingly useful for mycotoxins detection as a precursor to chemical analysis. Bioassay allows the analyst to make an informed decision when selecting a more detailed chemical analysis procedure. Various short-term in vitro biological assays have been employed to screen for the presence of several mycotoxins (Lompe and Milczewski, 1979; Coker, 1997). Problems encountered with these bioassays include the maintenance of animals or cell lines and cultures, technically complex procedures requiring extensive preparation or assay times or both, expensive materials, and subjective data analyses (Blaise, 1991) also. Recent toxicology, in accordance with recommendations from the European Council, has demanded decrease in the number of vertebrates used in toxicology testing and their partial replacement with invertebrate animals, plants or even organ, tissue, or cell cultures (Petr Dvorak et al., 2012). During the last 50 years, various invertebrate species have been tested for their sensitivity to many chemical or physical agents to prove their possible use for pre-screening tests. Brine shrimp larvae have been used to evaluate fungal toxins (Harwig and Scott, 1971). The lower sensitivity of the Artemia species to several chemical or physical agents in comparison with the other invertebrate test organisms, the decreased solubility of some chemical substances in saline or sea 
medium, in addition to the various conditions that control the test, such as temperature, $\mathrm{pH}$, chemical composition of the medium, oxygen, photoperiod, nutrients, some population effects, type of growth stage, etc may affect the toxicity results (Nalecz-Jawecki et al., 2003; GeorgeAres et al., 2003; Mayorga et al., 2010). Algae are especially suitable for biotests because of their sensitivity to environmental pollution and their abundance in aquatic systems. In addition, they have no roots as higher plants and reflect only the properties of the ambient water rather than those of the soil higher plants that are rooted. Also, algal biotests are simple and allow observing multiple generations (Danilov and Ekelund, 2000). The agar diffusion technique of Chlorella vulgaris, Ustilago maydize and Trichoderma viride used by Bean et al. (1992) showed that Chlorella was the most sensitive organism toward macrocyclic trichothecens produced by different Myrothecium species tested. Bacillus subtilis and $C$. vulgaris were proved to be particularly sensitive to mycotoxins (Sukroongreeung et al., 1984).

This study aimed to develop a rapid, easy, sensitive and reliable bioassay technique using optical density readings of liquid cultures of $C$. vulgaris to detect mycotoxic compounds.

\section{MATERIALS AND METHODES}

\section{Fungal isolates}

One hundred and eight isolates of filamentous fungi isolated from the air of intensive care units and operation rooms as well as the dust of air conditioning system filters in each of the Assiut University hospitals were collected and identified in Assiut University Mycological Center. Multiple of six isolates of each Aspergillus flavus, Aspergillus fumigatus, Aspergillus niger, Cladosporium cladosporioides, Fusarium solani, Fusarium oxysporum and Stachybotrys elegans were tested.

\section{Fungal crude extracts}

Each isolate was grown on Czapek's glucose agar medium under aseptic conditions, incubated at $25 \pm 2^{\circ} \mathrm{C}$ for 10 days. After the incubation period, the entire agar media with fungal mycelia were cut into small pieces, transferred to a $250 \mathrm{ml}$ Erlenmeyer flask containing $50 \mathrm{ml} \mathrm{96 \%} \mathrm{methanol.} \mathrm{The} \mathrm{contents} \mathrm{were} \mathrm{shaken} \mathrm{on} \mathrm{a}$ rotary shaker (200 rpm, $24 \mathrm{~h}$ ) and filtered through filter paper (Whatman No.1). The residue was then washed twice with $96 \%$ methanol (25 $\mathrm{ml}$ each). The methanol extracts were combined, dried over anhydrous sodium sulphate, and then left to evaporate to near dryness under vacuum. The residues were transferred quantitatively to a dram vial with the minimal amount of methanol and evaporated to near dryness (Bean et al., 1992).

\section{Thin layer chromatographic (TLC) determination of mycotoxins}

For qualitative determination of mycotoxin produced by different fungal isolates tested, TLC technique adopted by El- kady and Moubasher (1982) was employed.

\section{Biological assay procedure}

\section{Bacillus subtilis}

The disc diffusion method (Sleigh and Timburg, 1981) was used to measure the antibacterial activities of different isolates crude extract on $B$. subtilis and the inhibition zone was measured.

\section{Chlorella vulgaris}

The strain of $C$. vulgaris used in this investigation was obtained from Laboratory of Microbiology, Department of Botany and Microbiology, University of Assiut. For growth and enrichment, Beijrinek medium was used (Stein, 1966). Algal cultures were grown at a temperature of $28 \pm 1{ }^{\circ} \mathrm{C}$ in a light growth chamber (Forma Scientific, USA). The inoculums were maintained to be 0.123 O.D. $750 \mathrm{~nm}$ in all the cultures throughout the study period. Three replicates of 10 $\mu \mathrm{l}$ of the clean crude extract tubes and $6 \mathrm{ml}$ of Chlorella culture was added to each tube under a septic conditions, optical density (O.D. $750 \mathrm{~nm}$ ) of cultures was measured at required time intervals (after 24, 48 and 72 h) using spectrophotometer Thermo scientific, evolution 160 UV-Vis, double beam spectrophotometer, USA.

\section{Data analysis}

The results were analysed by one way analysis of variance (ANOVA) followed by Newman-Keuls Multiple Comparison Test as a post-test using computer prism program for windows, version 3.0 (Graph pad software, Inc, San Diago CA. USA). The significant difference between the tested groups was accepted at $p<0.05,0.01$ or 0.001 , the data were expressed as mean \pm standard error (SE) and the number of isolates $(n)$ was the multiples of six.

\section{RESULTS AND DISCUSSION}

The TLC analysis of the 108 crude extracts showed that only 78 of the fungal isolates that were tested had the ability to produce at least one of these mycotoxic compounds (Aflatoxins $B_{1}, B_{2}, G_{1}, G_{2}$ Gliotoxin, fumigillin, $T_{2}$, zearalenone, Roridins $A$ and $E$, verrucarins $A$ and $J$, Trichoveroids, Satratoxins $\mathrm{H}$ and $\mathrm{E}$ ).

The crude extracts of all toxin producing fungal isolates that were tested according to the TLC analysis inhibited the growth of $C$. vulgaris dramatically after 48 and $72 \mathrm{~h}$ of which $F$. oxysporum and $S$. elegans were the fungal isolates that affected the growth of $C$. vulgaris the most as compared to the control (Figure 1B and C). Although, the growth of $C$. vulgaris was significantly affected after $24 \mathrm{~h}$, the most fungal isolates were $A$. fumigatusand $F$. oxysporum (Figure 1A). On the other hand, the crude extracts of the thirty nontoxin producing fungal isolates that were tested showed no significant inhibition of $C$. vulgaris at the three time intervals used when compared with the control (Figure 1D, E and F). These results are in a agreement with those obtained by Bean et al. (1992) in which $C$. vulgaris proved to be the most sensitive organism to macrocyclic tichothecenes produced by Myrothecium species. Youssef et al. (2008) found that 14 out of 60 peanut seed samples that were tested inhibited the growth of $C$. vulgaris. 
Toxin producing fungal species that were tested

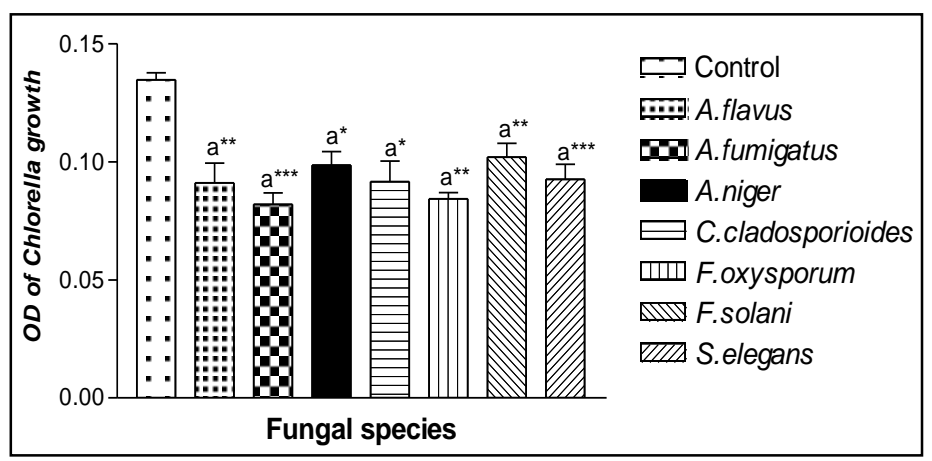

(A)

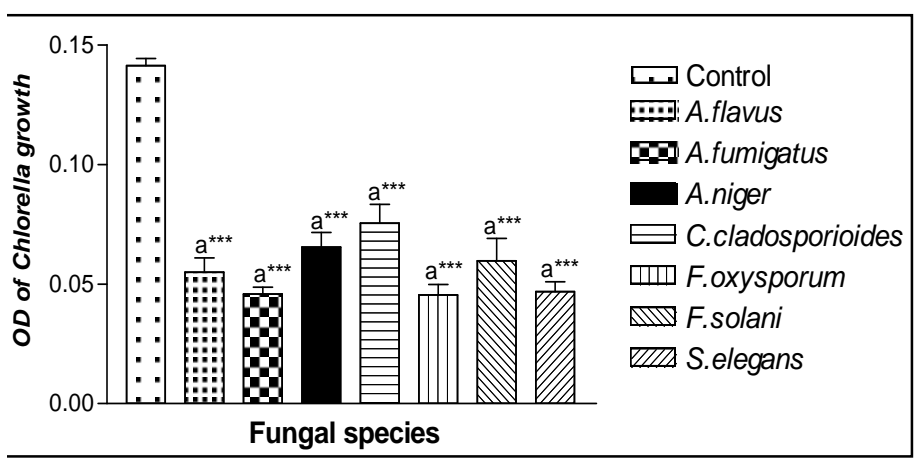

(B)

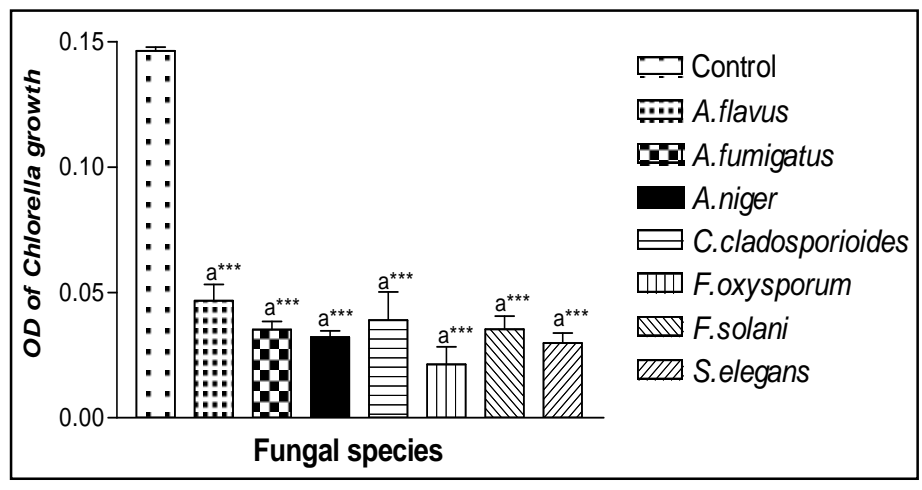

(C) nontoxin producing fungal species that were tested

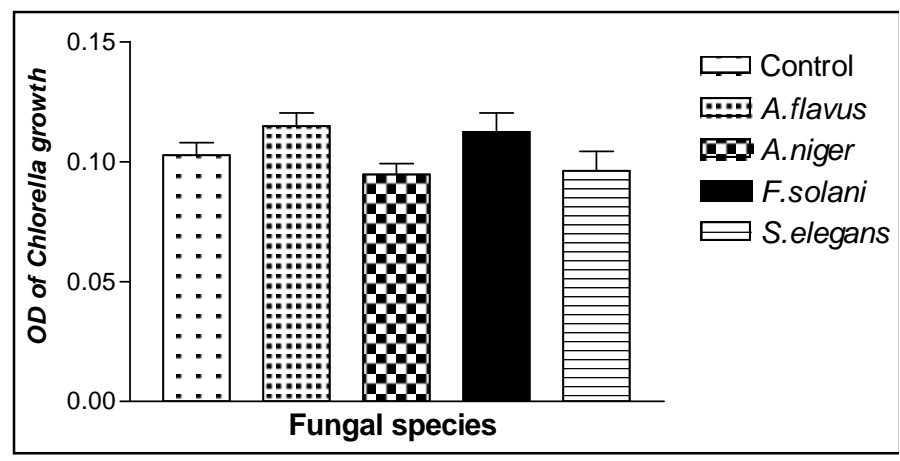

(D)

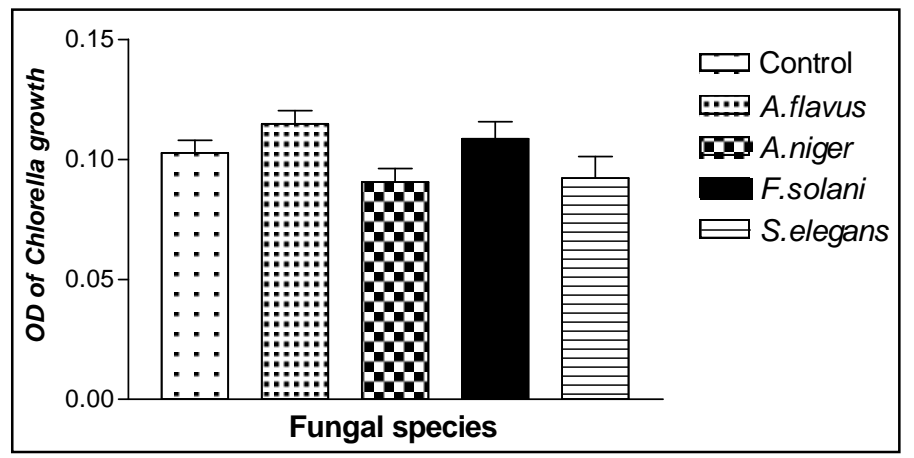

(E)

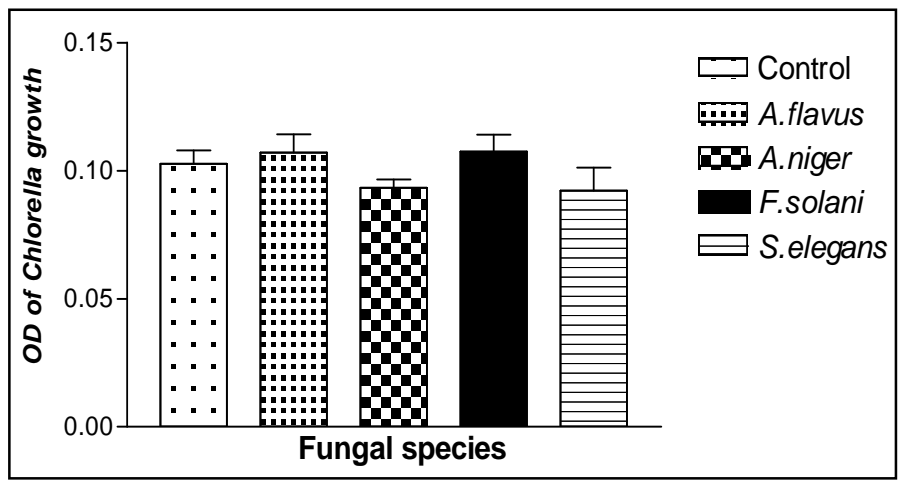

(F)

Figure 1. OD of $C$. vulgaris growth inhibited by the crude extracts of fungal isolates that were tested after $24 \mathrm{~h}(\mathrm{~A}$ and $\mathrm{D}), 48 \mathrm{~h}(\mathrm{~B}$ and $\mathrm{E})$ and $72 \mathrm{~h}(\mathrm{C}$ and $\mathrm{F})$ of incubation. $\mathrm{a}=$ Significant difference between control group and fungal species. ${ }^{*}=\mathrm{P}<0.05 ;{ }^{* *}=\mathrm{P}<0.01 ;{ }^{* \star *}=\mathrm{P}<0.001$.

When the disk diffusion method (Sleigh and Timburg, 1981) was used to evaluate the antibacterial activity of the 78 fungal crude extracts of the toxic fungal, isolates on $B$. subtilis showed highly significant inhibition zone of which $S$. elegans, $A$. fumigatus and $A$. flavus were the most toxic isolates used (Figure 2). Several Bacillus species have been shown to be sensitive to other mycotoxins (Madhyastha et al., 1994). There was a great diversity in the response of the bacterial strains to fusaric acid; however, asagroup, Bacillusspeciesand Paenibacillus macerans were much more sensitive to fusaric acid than
Pseudomonas species (Landa et al., 2002). Relative insensitivity of aflatoxin B towards $B$. subtills has been reported by Eka and Zo (1972). Reiss (1975) reported that the bioassay of patulin with $B$. subtills spores can be recommended as a sensitive technique to supplement TLC identification. In addition, Aboul-Nasr and Abdul-Rahman (2013) found that Gram positive bacteria (Bacillus cereus and $B$. subtilis) especially $B$. subtilis showed the highest sensitivity towards 76 Fusarium isolates producing $\mathrm{FB}_{1}$ and $\mathrm{FB}_{1}$ plus $\mathrm{FB}_{2}$ tested.

The results of $C$. vulgaris were confirmed by those of 


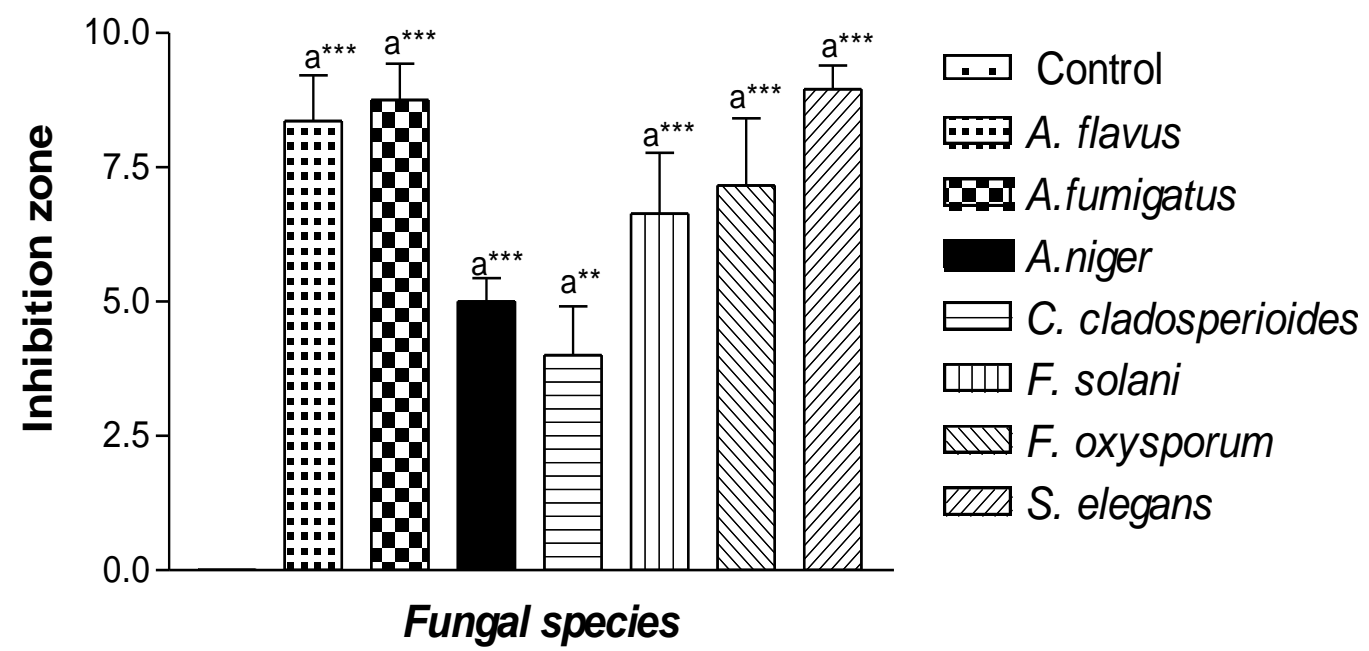

Figure 2. The inhibition zone of $B$. subtilis growth by toxin producing fungal isolates that were tested. A = Significant difference between control group and each fungal species group. ${ }^{*}=\mathrm{P}<0.05 ;{ }^{* *}=\mathrm{P}<$ $0.01{ }^{* * *}=\mathrm{P}<0.001$.

bacteria by the proportional resemblance according to the method used either by the increase of inhibition zone in bacteria or the decrease of growth in $C$. vulgaris.

\section{Conclusion}

The results obtained by $C$. vulgaris procedure demonstrated a reliable short-term method for assessing the toxicity of mycotoxins and it can be performed easily.

\section{REFERENCES}

Aboul-Nasr MB, Abdul-Rahman M (2013). Biological and chemical assay for detecting fumonisins produced by Fusarium verticillioides isolates collected from Egypt. Microbiology 159 (Pt 8):1720-4.

Bean GA, Jarvis BB, Aboul-Nasr MB (1992). A biological assay for the detection of Myrothecium spp. produced macrocyclic trichothecenes. Mycopathologia 119 (3):175 - 180

Blaise C (1991). Microbiotests in Aquatic Toxicology: Characteristics, Utility and Prospects. J. Environ. Toxicol. Water Qual. 6 (2): 145-155.

Coker RD (1997). Mycotoxins and their control: constraints and opportunities. NRI bulletin 73. Natural Resources Institute, Chatham, Kent, United Kingdom.

Danilov R, Ekelund N (2000). Applicability of Growth Rate, Cell Shape, and Motility of Euglena gracilis as Physiological Parameters for Bioassessment at Lower Concentrations of Toxic Substances: An Experimental Approach. Mid Sweden University, John Wiley \& Sons, Inc., Ha"rno" sand, Sweden.

Eka OU, Zo Allg. (1972). Effects of aflatoxin on microorganisms. Allg. Microbiology. 12: 593.

El-kady IA, Moubasher MH (1982). Toxigenicity and toxin of Stachybotrys chartarum isolates from wheat straw samples in Egypt. J. Exp. Mucol. 6: 25-31.

George-Ares A, Febbo EJ, Letinski DJ, Yarusinsky J, Safadi RS, Aita AF (2003). Use of Brine Shrimp (Artemia) in Dispersant Toxicity Tests: Some Caveats. In: Proceedings of International Oil Spill Conference.

Harwig J, PM Scott (1971). Brine shrimp (Artemia salina L.) larvae as a screening system for fungal toxins. J. Appl. Microbiol. 21:1011-1016.

Landa BB, Cachinero-Diaz JM., Lemanceau P. Jimenez-Diaz RM, Alabouvette C (2002). Effect of fusaric acid and phytoanticipins on growth of rhizobacteria and Fusarium oxysporum. J. Microbiol. 48: 971-985.

Lompe A, Milczewski KEv (1979). Ein zellkultur-test fur den Nachweis von Mykotoxinen. Z. Lebensm. Unters. Forsch. 169: 249-254.

Madhyastha MS, Marquardt RR, Masi A, Borsa J, Frohlich AA (1994). Comparison of toxicity of different mycotoxins to several species of bacteria and yeasts: Use of Bacillus brevis in a disc diffusion assay. J. Food Prot. 57: 48 \pm 53 .

Mayorga P, Pérez KR, Cruz SM, Cceres S (2010). Comparison of Bioassays using the Anostracan Crustaceans Artemia salina and Thamnocephalus platyurus for Plant Extract Toxicity Screening. Revista Brasileira de Farmacognosia. J. Pharmacogn. 20 (6): $897-$ 903.

Nalecz-Jawecki G, Grabinska-Sota E, Narkiewicz P (2003). The Toxicity of Cationic Surfactants in four Bioassays. J. Ecotoxicol. Environ. Saf. 54(1): 87-91.

Petr Dvorak, Katarina Benova, Jiri Vitek (2012). Alternative Biotest on Artemia franciscana. J. Ecotoxicol. Environ. Saf. 51-74

Reiss J (1975). Bacillus subtilis; A Sensitive Bioassay for Patulin. J. Bull. Environ. Contam. Toxicol. 13 (6): 689-691.

Sleigh ZA, Timburg MC (1981). Notes on medical bacteriology. Churchill. Living Stone. p. 43.

Sukroongreeung S, KT Schappert, GG Khatchatourians (1984). Survey of sensitivity of twelve yeast genera toward T-2 toxin. Appl. Environ. J. Microbiol. 48: 416-419.

Van Egmond HP, Speijers GA (1999). Natural toxins I. Mycotoxins., International Food Safety Handbook, Science, International Regulation and Control. Marcel Dekker. pp. 342-355.

Youssef MS, El-Maghraby OMO, Rahim YM (2008). Mycobiota and mycotoxins in Egyptian peanut (Arachis hypogeal L.) seeds. J. Bot. 4 (4): 349:360. 